\title{
Persistent Spinal Pain Syndrome: New Terminology for a New Era
}

\author{
Erika A Petersen (ID) \\ Michael E Schatman (D) ${ }^{2-4}$ \\ Dawood Sayed (iD ${ }^{5}$ \\ Timothy Deer (iD ${ }^{6}$ \\ 'Department of Neurosurgery, \\ University of Arkansas for Medical \\ Sciences, Little Rock, AR, USA; \\ ${ }^{2}$ Department of Diagnostic Sciences, \\ Tufts University School of Dental \\ Medicine, Boston, MA, USA; \\ ${ }^{3}$ Department of Public Health and \\ Community Medicine, Tufts University \\ School of Medicine, Boston, MA, USA; \\ ${ }^{4}$ School of Social Work, North Carolina \\ State University, Raleigh, NC, USA; \\ ${ }^{5}$ Department of Anesthesiology and Pain \\ Medicine, The University of Kansas \\ Medical Center, Kansas City, KS, USA; \\ ${ }^{6}$ Spine and Nerve Center of the Virginias, \\ Charleston, WV, USA
}

Pain medicine and treatment of chronic pain have evolved, with many new treatment options developed just in the past decade. Leaders in pain medicine recognize that terminology needs to keep up with our understanding of disorders, their pathophysiologies, and their treatment. In the 1990s, the term "complex regional pain syndrome" (CRPS) emerged from the work of an expert group convened by the International Association for the Study of Pain (IASP). The goal was an improved term for the conditions previously labeled "reflex sympathetic dystrophy" and "causalgia" that was more general and not specific to a certain pathophysiology. This effort also delineated the subtypes of complex regional pain syndrome. Despite the expert recommendation, there were objections from several fronts to the terminology, and adoption of the term was slow. ${ }^{1}$ An analysis of publications from 2001 to 2012 identified that $79 \%$ used the new terminology, with a gradual increase over the time period. ${ }^{2}$

The terms "post-laminectomy syndrome" and "failed back surgery syndrome" (FBSS) were coined in the 1970s and then gained traction in the 1980s amid a discussion in the literature of approaches to treat persistent pain after spinal surgery. However, the terms are ambiguous, addressing a heterogeneous group of disorders that share the commonality of chronic pain and the experience of prior surgery after which pain either recurs or persists.

In a 2015 analysis, Al-Kaisy et al noted that the term "failed back surgery syndrome" is pejorative and ought to be changed. ${ }^{3}$ Without doubt, the term is rife with ethical implications. Progressively, it is apparent that patients with nonspecific back and other types of chronic pain are stigmatized and marginalized. ${ }^{4-6}$ Compounding matters, it has been argued that this stigmatization and marginalization has likely been exacerbated by the ongoing COVID-19 crisis. $^{7}$ The impact of stigmatization and marginalization of these unfortunate patients has been devastating, including the deterioration of pain sufferers' trust in health care professionals, ${ }^{8}$ quality of the pain care that patients receive, ${ }^{9}$ perceived injustice (which has recently been empirically related to greater pain severity and increased functional impairment), ${ }^{10}$ and exacerbated psychological distress ${ }^{11}$ including increased depression and anxiety. ${ }^{12}$

Many patients whose pain is not substantially reduced by low back surgeries, irrespective of the reason, have few treatment options other than chronic opioid therapy. That there exists a copious body of literature demonstrating that opioid reliance exacerbates the stigmatization and marginalization ${ }^{13-17}$ of these patients is
Correspondence: Michael E Schatman $\mathrm{Tel}+\mathrm{I}$ 425-647-4880

Email Michael.Schatman@tufts.edu 
not surprising. Society uses a number of unflattering terms for those who are opioid-dependent, irrespective of whether they are medical or recreational users. Those who have a negative opinion on opioid use have done their best to influence policymakers and shame medical opioid users in a misguided effort to curb the illicit opioid crisis with which the United States is currently faced. ${ }^{18,19}$

Additionally, the word "failed" in "failed back surgery syndrome" is ambiguous, which creates another ethical imbroglio. Due to its ambiguity, the question of whether the surgeon or the patient is "responsible" for the "failure" is not clearly answered. In the American pain care system, there exists the perception that blame for an inability to achieve symptom management is generally placed on the patient by the clinician. ${ }^{20}$ Carr noted that, "Patients with pain need less stigma, not more." ${ }^{21}$ Perhaps by replacing the rather draconian term, "failed back surgery syndrome" with a less pejorative and more accurate one will help Dr Carr's beliefs regarding pain patients' well-being become a reality.

In 2019, the IASP published a new classification of chronic pain, which will be incorporated within the International Classification of Disease (ICD-11). ${ }^{22}$ The IASP recommendations eliminate certain terminology such as FBSS in favor of "chronic pain after spinal surgery" (CPSS). As with the unveiling of the CRPS terminology in 1994, concerns have arisen about the categories and subdivisions within the IASP framework for chronic pain. While the elimination of the FBSS terminology may be welcome, the new framework does not fully account for all patients with chronic spinal pain. Therefore, an expert group of pain practitioners and neurosurgeons undertook its own process to identify better delineated labels that would specifically address the insufficiency of terminology to address surgical status of patients with spinal pain while replacing the problematic terminology of "failed back surgery syndrome". ${ }^{23}$ The proposed replacement terminology, "persistent spinal pain syndrome," (PSPS) is divided into Type 1 (no surgery performed) and Type 2 (postsurgery). The IASP task force recommendations, while rejecting the non-sensical and non-diagnostic term FBSS, seem to fall short. The consensus committee makes an improvement with PSPS and the recommended subtypes and coding strategy.

The shift in medical culture required for the transition in terminology related to chronic pain will require time, and there are many issues as identified in the IASP article. Christelis et al state it clearly:
The wide and well-established use of the term FBSS by clinicians, in the published literature and by insurance carriers, the biomedical industries, commissioning and regulatory bodies, and government agencies will make its replacement complex and challenging.

Actually, that is an understatement. All of the existing literature uses a cohort defined in the traditional sense of FBSS beginning with seminal works of North ${ }^{24}$ and Kumar et $\mathrm{al}^{25}$ and carrying through to all of the more recent studies.

Access to some treatments is dependent on the diagnosis. For example, patients who are candidates for spinal cord stimulation often must carry a diagnosis of FBSS for insurance to cover the procedure. While many insurers may use the ICD-10 term "post laminectomy syndrome", it is viewed as synonymous with FBSS and remains the requirement for payment by many. Because payers require this specific diagnosis for access to many advanced pain treatments such as neuromodulation, patients may be directed inappropriately towards surgery when it is not clinically prudent, yet is the only available covered option. There is an opportunity to improve access to treatment if diagnostic specificity is improved. By changing terminology, we better describe the clinical circumstance of the patient and his/her appropriateness for a specific treatment. Consider, for example, a patient who may have undergone all reasonable minimally invasive non-surgical spinal procedures and is not a candidate for spinal surgery. In these cases, because the patient has not undergone a laminectomy - and even though all medically appropriate interventions have been exhausted - the patient may not be able to access a trial of spinal cord stimulation due to insurance restrictions. The outmoded definition of FBSS impedes patient access to another avenue of pain treatment, for which the patient might be eligible if he or she were PSPS Type 1. Unfortunately, the converse is also likely. The potential unintended consequence of updating the ICD may be that payers will have new opportunities to deny coverage for patients currently covered but not so when the diagnoses become more granular.

The arrival of the new ICD-11 terminology will provide further clarity in communicating patients' clinical circumstances. The recent proposal to adopt PSPS to describe patients with persistent spinal pain that may be amenable to interventional pain and neuromodulation treatments is valid and offers some benefits over the more general IASP terminology. Regardless of whether it 
is CPSS (it has been adopted for implementation, but not until January 2022) or PSPS that becomes the final rubric, it will take some time to integrate. It is our obligation to design trials with better alignment of trial cohort characteristics to these diagnosis terms and to understand the cohorts of chronic spinal pain patients using these terms as effectively as possible. As such, the Journal of Pain Research and the American Society of Pain and Neuroscience support the new terminology of PSPS to improve the research and treatment, and reduce the stigmatization of this patient population.

\section{Disclosure}

Dr Erika A Petersen reports grants, personal fees for clinical research support and consulting from Nevro; grants for clinical research support and/or consulting from Saluda Medical, Neuros Medical, and ReNeuron; personal fees for consulting from Abbott Neuromodulation, Medtronic, and Vertos Medical; also reports personal fees for being part of the board of directors for and stock options from SynerFuse, outside the submitted work. Dr Michael E Schatman is a research consultant for Modoscript, outside the submitted work. Dr Timothy Deer is a consultant for Abbott, Vertos, Axonics, Flowonix, SpineThera, Saluda Medical, Nalu, Medtronic, Nevro, SI Bone, Stimgenics, SPR Therapeutics, Cornerloc, Boston Scientific, PainTeq, Ethos, and Vertiflex. He works with these companies to treat chronic pain but not related to this manuscript. The authors report no other conflicts of interest in this work.

\section{References}

1. Dutton K, Littlejohn G. Terminology, criteria, and definitions in complex regional pain syndrome: challenges and solutions. J Pain Res. 2015;8:871-877. doi:10.2147/JPR.S53113

2. Todorova J, Dantchev N, Petrova G. Complex regional pain syndrome acceptance and the alternative denominations in the medical literature. Med Princ Pract. 2013;22(3):295-300. doi:10.1159/000343905

3. Al Kaisy A, Pang D, Desai MJ, et al. Failed back surgery syndrome: who has failed? Neurochirurgie. 2015;61(Suppl 1):S6-S14. doi:10.1016/j.neuchi.2014.10.107

4. De Ruddere L, Craig KD. Understanding stigma and chronic pain: a-state-of the-art review. Pain. 2016;157(8):1607-1610. doi:10.1097/j. pain.0000000000000512

5. Jain AR. Commentary: pain, stigma, and the politics of self-management. Pain Med. 2020;21(5):888-890. doi:10.1093/pm/ pnaa064

6. Goldberg DS. Toward fair and humane pain policy. Hastings Cent Rep. 2020;50(4):33-36. doi:10.1002/hast.1170

7. Karos K, McParland JL, Bunzli S, et al. The social threats of COVID-19 for people with chronic pain. Pain. 2020;161 (10):2229-2235. doi:10.1097/j.pain.0000000000002004
8. Buchman DZ, Ho A, Goldberg DS. Investigating trust, expertise, and epistemic injustice in chronic pain. J Bioeth Inq. 2017;14(1):31-42. doi:10.1007/s11673-016-9761-x

9. Roche J, Harmon D. Exploring the facets of empathy and pain in clinical practice: a review. Pain Pract. 2017;17(8):1089-1096. doi: $10.1111 /$ papr. 12563

10. Penn TM, Overstreet DS, Aroke EN, et al. Perceived injustice helps explain the association between chronic pain stigma and movement-evoked pain in adults with nonspecific chronic low back pain. Pain Med. 2020;21(11):3161-3171. doi:10.1093/pm/pnaa095

11. Nicola M, Correia H, Ditchburn G, et al. Invalidation of chronic pain: a thematic analysis of pain narratives. Disabil Rehabil. 2021;43 (6):861-869. doi:10.1080/09638288.2019.1636888

12. Rodero B, Luciano JV, Montero-Marín J, et al. Perceived injustice in fibromyalgia: psychometric characteristics of the Injustice Experience Questionnaire and relationship with pain catastrophising and pain acceptance. J Psychosom Res. 2012;73:86-91. doi:10.1016/j. jpsychores.2012.05.011

13. Brooks EA, Unruh A, Lynch ME. Exploring the lived experience of adults using prescription opioids to manage chronic noncancer pain. Pain Res Manag. 2015;20(1):15-22. doi:10.1155/2015/314184

14. McCradden MD, Vasileva D, Orchanian-Cheff A, et al. Ambiguous identities of drugs and people: a scoping review of opioid-related stigma. Int $J$ Drug Policy. 2019;74:205-215. doi:10.1016/j. drugpo.2019.10.005

15. De Sola H, Maquibar A, Failde I, et al. Living with opioids: a qualitative study with patients with chronic low back pain. Health Expect. 2020;23(5):1118-1128. doi:10.1111/hex.13089

16. Dassieu L, Heino A, Develay E, et al. "They think you're trying to get the drug": qualitative investigation of chronic pain patients' health care experiences during the opioid overdose epidemic in Canada. Can J Pain. 2021;5(1):66-80. doi:10.1080/24740527.2021.1881886

17. Dassieu L, Heino A, Develay É, et al. Conversations about opioids: impact of the opioid overdose epidemic on social interactions for people who live with chronic pain. Qual Health Res. 2021:10497323211003063. doi:10.1177/10497323211003063

18. Singer JA, Sullum JZ, Schatman ME. Today's nonmedical opioid users are not yesterday's patients: implications of data indicating stable rates of nonmedical and pain reliever use disorder. J Pain Res. 2019;12:617-620. doi:10.2147/JPR.S199750

19. Schatman ME, Shapiro H. Damaging state legislation regarding opioids: the need to scrutinize sources of inaccurate information provided to lawmakers. J Pain Res. 2019;12:3049-3053. doi:10.2147/JPR.S235366

20. Walker J, Holloway I, Sofaer B. In the system: the lived experience of chronic low back pain from the perspectives of those seeking help from pain clinics. Pain. 1999;80:621-628. doi:10.1016/S03043959(98)00254-1

21. Carr DB. Patients with pain need less stigma, not more. Pain Med. 2016;17(8):1391-1393. doi:10.1093/pm/pnw158

22. Treede RD, Rief W, Barke A, et al. Chronic pain as a symptom or a disease: the IASP classification of chronic pain for the international classification of diseases (ICD-11). Pain. 2019;160(1):19-27. doi:10.1097/j.pain.0000000000001384

23. Christelis N, Simpson B, Russo M, et al. Persistent spinal pain syndrome: a proposal for failed back surgery syndrome and ICD-11. Pain Med. 2021;22(4):807-818. doi:10.1093/pm/pnab015

24. Bell GK, Kidd D, North RB. Cost-effectiveness analysis of spinal cord stimulation in treatment of failed back surgery syndrome. J Pain Symptom Manage. 1997;13(5):286-295. doi:10.1016/S08853924(96)00323-5

25. Kumar K, North R, Taylor R, et al. Spinal cord stimulation vs. conventional medical management: a prospective, randomized, controlled, multicenter study of patients with Failed Back Surgery Syndrome (PROCESS Study). Neuromodulation. 2005;8 (4):213-218. doi:10.1111/j.1525-1403.2005.00027.x 


\section{Publish your work in this journal}

The Journal of Pain Research is an international, peer reviewed, open access, online journal that welcomes laboratory and clinical findings in the fields of pain research and the prevention and management of pain. Original research, reviews, symposium reports, hypothesis formation and commentaries are all considered for publication. The manuscript management system is completely online and includes a very quick and fair peer-review system, which is all easy to use. Visit http:// www.dovepress.com/testimonials.php to read real quotes from published authors. 